\title{
Ambient ultraviolet radiation exposure and hepatocellular carcinoma incidence in the United States
}

\author{
Trang VoPham ${ }^{1,2^{*}}$ D, Kimberly A. Bertrand ${ }^{3}$, Jian-Min Yuan ${ }^{4,5}$, Rulla M. Tamimi ${ }^{1,2}$, Jaime E. Hart ${ }^{2,6}$ \\ and Francine Laden ${ }^{1,2,6}$
}

\begin{abstract}
Background: Hepatocellular carcinoma (HCC), the most commonly occurring type of primary liver cancer, has been increasing in incidence worldwide. Vitamin D, acquired from sunlight exposure, diet, and dietary supplements, has been hypothesized to impact hepatocarcinogenesis. However, previous epidemiologic studies examining the associations between dietary and serum vitamin $\mathrm{D}$ reported mixed results. The purpose of this study was to examine the association between ambient ultraviolet (UV) radiation exposure and HCC risk in the U.S.

Methods: The Surveillance, Epidemiology, and End Results (SEER) database provided information on HCC cases diagnosed between 2000 and 2014 from 16 population-based cancer registries across the U.S. Ambient UV exposure was estimated by linking the SEER county with a spatiotemporal UV exposure model using a geographic information system. Poisson regression with robust variance estimation was used to calculate incidence rate ratios (IRRs) and 95\% confidence intervals (Cls) for the association between ambient UV exposure per interquartile range (IQR) increase $\left(32.4 \mathrm{~mW} / \mathrm{m}^{2}\right)$ and $\mathrm{HCC}$ risk adjusting for age at diagnosis, sex, race, year of diagnosis, SEER registry, and county-level information on prevalence of health conditions, lifestyle, socioeconomic, and environmental factors.

Results: Higher levels of ambient UV exposure were associated with statistically significant lower HCC risk ( $n=56,245$ cases; adjusted IRR per IQR increase: $0.83,95 \% \mathrm{Cl} 0.77,0.90 ; p<0.01$ ). A statistically significant inverse association between ambient UV and HCC risk was observed among males ( $p$ for interaction $=0.01$ ) and whites ( $p$ for interaction $=0.01$ ).
\end{abstract}

Conclusions: Higher ambient UV exposure was associated with a decreased risk of HCC in the U.S. UV exposure may be a potential modifiable risk factor for HCC that should be explored in future research.

Keywords: Ultraviolet radiation, Liver cancer, Hepatocellular carcinoma, Geographic information system

\section{Background}

Hepatocellular carcinoma (HCC) is the most commonly diagnosed histological type of primary liver cancer [1]. HCC accounts for between 85 and $90 \%$ of primary liver cancer cases [2]. Risk factors for HCC include chronic hepatitis B virus $(\mathrm{HBV})$ infection and exposure to aflatoxin

\footnotetext{
* Correspondence: tvopham@hsph.harvard.edu

'Department of Epidemiology, Harvard T.H. Chan School of Public Health, Boston, MA, USA

${ }^{2}$ Channing Division of Network Medicine, Department of Medicine, Brigham and Women's Hospital and Harvard Medical School, Boston, MA, USA

Full list of author information is available at the end of the article
}

in parts of Asia and sub-Saharan Africa; chronic hepatitis $\mathrm{C}$ virus (HCV) infection is the predominant risk factor in Japan and Egypt [3]. In the U.S. and Europe, risk factors include chronic HCV infection, heavy alcohol consumption, obesity, diabetes, and metabolic syndrome [3]. Other risk factors include non-alcoholic fatty liver disease (and nonalcoholic steatohepatitis) and cigarette smoking; physical activity and coffee and tea consumption may be protective $[1,3-6]$. Liver cancer incidence has been increasing across many areas around the world including the U.S. [7]. Approximately $40.5 \%$ of $\mathrm{HCC}$ cases in the U.S. remain 
unexplained by established risk factors such as HCV, HBV, alcohol consumption, diabetes, and obesity [8].

Emerging evidence suggests that vitamin D may impact HCC risk. Vitamin D is a hormone acquired from sunlight exposure, diet, and dietary supplements that plays a major role in human health [9-12]. Vitamin D from the skin and diet is metabolized in the liver to the major circulating form 25-hydroxyvitamin D (25(OH)D) [11]. Experimental evidence has demonstrated that vitamin D exhibits many anti-hepatocarcinogenic activities including regulating bile acid levels through vitamin D receptor (VDR) [13-15]. However, the few epidemiologic studies that have examined the association between dietary and serum vitamin D and liver cancer risk while adjusting for liver cancer risk factors have shown mixed results - inverse, positive, and null associations [16-18].

Vitamin D exposure can be assessed by its concentration in blood, amount consumed through diet and dietary supplements, and estimated from self-reported sun exposure and location-based ambient ultraviolet (UV) radiation exposure $[19,20]$. The primary source of bioactive vitamin $\mathrm{D}$ in humans is production in skin upon solar UV-B (280-315 nm) exposure [10]; approximately $90 \%$ of circulating levels of vitamin D are attributed to sunlight exposure [19]. Previous epidemiologic studies have estimated long-term vitamin D status using satellite remote sensing images of UV combined with location of residence (e.g., geocoded residential addresses) using geographic information systems (GIS), an exposure metric that has been predictive of cancer risk, showing protective associations for colon cancer and nonHodgkin lymphoma [20-27]. While there is strong biological plausibility, to date, no epidemiologic studies have examined the possible association between personal or ambient UV exposure and the risk of developing HCC. The objective of this study was to evaluate the association between ambient UV exposure and HCC risk in the U.S.

\section{Methods}

\section{Study population}

The U.S. National Cancer Institute Surveillance, Epidemiology, and End Results (SEER) program collects individual-level information on cancer incidence, treatment, and survival from population-based cancer registries covering $28 \%$ of the U.S. population, including information on patient demographics, county at diagnosis, primary tumor site, and tumor morphology [28, 29]. The following registries were included in this analysis: (1) Atlanta (metropolitan); (2) Greater California; (3) Connecticut; (4) Detroit (metropolitan); (5) Greater Georgia; (6) Iowa; (7) Kentucky; (8) Los Angeles; (9) Louisiana (excluding July-December 2005 cases due to Hurricanes Katrina and Rita); (10) New Jersey; (11) New
Mexico; (12) Rural Georgia; (13) San Francisco-Oakland; (14) San Jose-Monterey; (15) Seattle (Puget Sound); and (16) Utah. All counties located in the catchment areas captured by these 16 SEER registries were included in the analysis. The Alaska Natives, Arizona Indians, Cherokee Nation, and Hawaii registries were excluded as UV exposure data were not available outside of the contiguous U.S. and the Alaska Natives, Arizona Indians, and Cherokee Nation registries only collect information on American Indian/Alaska Native populations. To protect patient confidentiality, the SEER database does not include personal identifiers; this study was exempt from Institutional Review Board (IRB) review.

\section{Case ascertainment}

HCC cases were defined using the following criteria: International Classification of Diseases for Oncology, Third Edition (ICD-O-3) topography code C22.0 (primary liver cancer) and ICD-O-3 histology codes 8170 to 8175 [30]; diagnostic confirmation (e.g., positive histology) excluding clinical diagnosis only [31]; sequence number of one primary only; diagnosis between 2000 and 2014; and not reported via autopsy or death certificate only [32]. As conducted in previous epidemiologic studies of UV and cancer in SEER, for each county, counts of HCC cases were stratified by age at diagnosis (<65 years; $\geq 65$ ); sex (male, female); race (white, black, Asian/Pacific Islander/American Indian/Alaska Native); year of diagnosis (2000-2007, 2008-2014); and SEER registry $[33,34]$.

\section{Exposure assessment}

Ambient UV exposure was estimated for each county in the study area using a high spatiotemporal resolution UV model [35]. The model was created using area-topoint residual kriging to downscale National Aeronautics and Space Administration (NASA) erythemal UV satellite remote sensing images from the Total Ozone Mapping Spectrometer (TOMS) and Ozone Monitoring Instrument (OMI) satellite sensors. The UV model incorporated information on surface albedo, aerosol optical depth, cloud cover, dew point, elevation, ozone, surface incoming shortwave flux, sulfur dioxide, and latitude. The UV model predicts average July noon-time erythemal UV irradiance $\left(\mathrm{mW} / \mathrm{m}^{2}\right)$. Erythemal UV incorporates UV-A and UV-B wavelengths (involved in vitamin $\mathrm{D}$ production) to calculate a measure describing the relative effectiveness of UV to induce erythema on Caucasian skin; shorter UV-B wavelengths are weighted more in the calculation [36, 37]. July erythemal UV has been predictive of risk for skin, colorectal, and other cancers in previous epidemiologic studies [22, 24, 25, 38], and during July, erythemal UV is strongest, aerosols and other noise factors are less influential, and satellite-based 
measures are in better agreement with ground-based measures $[25,35]$. The UV exposure model spans the contiguous U.S. The spatial resolution of the UV model is $1 \times 1 \mathrm{~km}$ and the temporal resolution is yearly from 1980 to 2015 .

Using U.S. county boundaries from 2000 [39], separately for each year from 1980 to 1999, the UV model was aggregated to the county level using GIS (i.e., UV raster cell centroids intersecting a given county were averaged to calculate a mean county UV value for each year). An annual county-level ambient UV average was calculated by averaging UV values from 1980 to 1999 , as well as for different exposure windows in 1980, 19801985, 1980-1990, and 1980-1995. Annual average ambient UV values were linked with each county in the study area. The county at diagnosis was available for each case from SEER. All spatial analyses were conducted in ArcGIS (Esri, Redlands, CA) using the contiguous U.S. Albers equal area conic coordinate system (NAD83 datum; USGS version).

\section{Additional covariates}

The following information was ascertained from the SEER database: age at diagnosis, sex, race, year of diagnosis, SEER registry, and county at diagnosis for each case; and county-level educational attainment (percentage with a Bachelor's degree or higher), poverty (percentage of individuals below the poverty level), percentage unemployed, median household income, and percentage foreign born (proxy for HBV prevalence as HBV is endemic in parts of Asia and Africa [1]) from the 2000 U.S. Census Bureau Summary Files, and U.S. Department of Agriculture Rural-Urban Continuum Codes (codes 1-7: urban; 8-9: rural) $[29,40]$. The following county-level data were acquired from the Institute for Health Metrics and Evaluation (IHME), which were created by applying small area models to data from the Behavioral Risk Factor Surveillance System and/or National Health and Nutrition Examination Survey: sex-specific age-adjusted prevalence of any alcohol use in 2002 ( $\geq$ one drink of any alcoholic beverage in past 30 days), heavy alcohol use in 2005 (average $>1$ drink per day for women or $>2$ drinks per day for men in past 30 days), and binge drinking in 2002 ( $>4$ drinks for women or $>5$ drinks for men on a single occasion at least once in past 30 days) [41, 42]; sex-specific age-adjusted prevalence of total diagnosed and undiagnosed diabetes in 2000 (proportion of adults aged $\geq 20$ years who reported a previous diabetes diagnosis and/or have fasting plasma glucose $\geq 126 \mathrm{mg} / \mathrm{dL}$ and/or hemoglobin A1c $\geq 6.5 \%$ ) [43, 44]; sex-specific age-adjusted prevalence of any physical activity in 2001 (participation during the past month in any physical activities or exercises such as running, calisthenics, golf, gardening, or walking for exercise outside of work) and obesity in 2001 (body mass index [BMI] $\geq 30 \mathrm{~kg} / \mathrm{m}^{2}$ ) [45]; and sex-specific age-adjusted prevalence of total current smoking in 2000 (currently smoking cigarettes some days [daily or nondaily]) [46]. County-level age-adjusted drug poisoning-related mortality rates (ICD10 underlying cause-of-death codes X40-X44 [unintentional], X60-X64 [suicide], X85 [homicide], or Y10-Y14 [undetermined intent]) were obtained from two-stage hierarchical models applied to the National Vital Statistics System multiple cause-of-death mortality files [47, 48]. Drug poisoning mortality was used as a proxy for $\mathrm{HCV}$ prevalence as a substantial proportion of drug poisoning deaths are attributed to injection drug use, which is the primary route of HCV transmission in the U.S. [49, 50]. County-level sex-specific percentages of the population employed in outdoor occupations (agriculture, forestry, fishing, hunting, or construction) were acquired from the 2000 U.S. Census Bureau Summary File 3 [20]. Particulate matter air pollution $<2.5 \mu \mathrm{m}$ in diameter $\left(\mathrm{PM}_{2.5}\right)$ is an International Agency for Research on Cancer (IARC) group 1 human carcinogen and has been shown to be associated with liver cancer risk in experimental and epidemiologic studies [51-55]. The U.S. Environmental Protection Agency (EPA) Air Quality System database annual summary file for ambient $\mathrm{PM}_{2.5}\left(\mu \mathrm{g} / \mathrm{m}^{3}\right)$ in 2000 was downloaded. An interpolated raster surface of $\mathrm{PM}_{2.5}$ values was created using inverse distance weighting in ArcGIS; interpolated $\mathrm{PM}_{2.5}$ raster cell centroids were intersected with county boundaries to calculate annual average ambient $\mathrm{PM}_{2.5}$ exposures for each county [56]. All county-level data were compiled using Federal Information Processing Standard (FIPS) codes.

\section{Statistical analysis}

Poisson regression with a robust variance estimator was used to calculate incidence rate ratios (IRRs) and 95\% confidence intervals (CIs) for the association between ambient UV exposure and the risk of developing HCC. UV exposure was examined continuously per interquartile range (IQR) increase $\left(32.4 \mathrm{~mW} / \mathrm{m}^{2}\right)$; the IQR was calculated across all 607 counties captured in the SEER registry catchment areas included in the analysis [33, 34]. Restricted cubic regression splines were used to test for deviations from linearity. All models were adjusted for age at diagnosis, sex, race, year of diagnosis, and SEER Registry. The natural logarithm of the county population size acquired from the 2000 U.S. Census Bureau Summary File 3 was used as the offset in all models. Potential confounding was evaluated by adding each covariate or group of covariates to the model and noting its impact on the effect estimate for UV exposure. We explored effect modification by age, sex, race, year, any physical activity, obesity, heavy alcohol consumption, smoking, median household income, $\mathrm{PM}_{2.5}$, outdoor occupation, and urbanicity using stratified analyses; tests 
for interaction were performed by adding an interaction term to the model and using likelihood ratio tests to determine statistical significance. We performed sensitivity analyses stratifying by residential mobility using data on the percentage of the county population that stayed in the same house (no migration from 1995 to 2000) from the 2000 U.S. Census Bureau Summary File 1 provided in the SEER database (residing in counties where $\geq 51.9 \%$ [20th percentile of counties] of the population did not migrate vs. residing in counties where $<51.9 \%$ did not migrate). We also performed sensitivity analyses stratifying by region of residence, which was determined by grouping each county and associated SEER registry into the following U.S. Census Bureau regions: Northeast: Connecticut, New Jersey; South: Atlanta (metropolitan), Greater Georgia, Rural Georgia, Kentucky, Louisiana; Midwest: Detroit (metropolitan), Iowa; and West: Greater California, Los Angeles, San Francisco-Oakland, San Jose-Monterey, New Mexico, Seattle (Puget Sound), Utah [57]; examining the effect of exposure lags of at least 20 years (1980), 15 years (1980-1985), 10 years (1980-1990), and 5 years (1980-1995); using Poisson models with a random intercept for county to examine potential county-level clustering; and using scaled Poisson models based on the Pearson and deviance methods to account for overdispersion [58]. All statistical analyses were conducted using SAS (SAS Institute, Cary, NC).

\section{Results}

There were 56,245 HCC cases diagnosed between 2000 and 2014 included in the analysis. HCC cases were on average 62.4 years of age at diagnosis, predominantly male (77.1\%), white (68.5\%), resided in the Western U.S. (61.5\%), and were diagnosed between 2008 and 2014 (58.1\%) (Table $1)$. The majority of cases who were Asian or Pacific Islander (78.1\%) were reported by the four California registries, and the majority of cases who were American Indian or Alaskan Native (79.2\%) were reported by the Greater California, New Mexico, and Seattle registries. Using data from the underlying population from which HCC cases were sampled, HCC cases at the time of diagnosis resided in mostly urban counties (99.2\%) where an average of $8.3 \%$ of the population engaged in heavy alcohol consumption, 23.9\% smoked cigarettes, $25.7 \%$ were obese, and $11.4 \%$ had diabetes. Compared to all U.S. counties across the contiguous U.S. (Table 1), the counties in which the HCC cases resided were more likely to be urban areas characterized by higher average ambient UV levels, median household income, educational attainment, drug poisoning mortality, and prevalence of foreign-born individuals (Table 1). Figure 1 shows annual average ambient UV exposure categorized by quintiles calculated using all 607 counties included in the study (each color classification corresponds to a quintile). From 1980 to 1999, annual average ambient UV levels ranged between 150.4 and $270.1 \mathrm{~mW} / \mathrm{m}^{2}$. Higher UV levels were observed in the Western U.S. (counties in the California, New Mexico, Utah registries) and parts of Louisiana, while lower UV levels were observed in the Northeastern and Midwestern U.S. (Connecticut, Detroit, Iowa, Kentucky, New Jersey, and Seattle registries).

In basic models adjusting for age, sex, race, year, and SEER registry, higher ambient UV exposure was associated with lower HCC risk (IRR per IQR [32.4 $\left.\mathrm{mW} / \mathrm{m}^{2}\right]$ increase: $0.90,95 \%$ CI 0.81, 0.99; $p=0.04$ ) (Table 2). After further adjustment for county-level heavy alcohol consumption, smoking, obesity, diabetes, median household income, unemployment, urbanicity, and $\mathrm{PM}_{2.5}$, the inverse association between ambient UV exposure and HCC risk became stronger. An IQR increase in UV exposure was associated with a $17 \%$ lower risk of HCC (adjusted IRR 0.83, 95\% CI 0.77, 0.90; $p<0.01$ ). Restricted cubic regression splines did not show evidence of deviations from linearity for the dose-response $(p=0.10)$. Model building is shown in Additional file 1: Table S1.

There were statistically significant interactions between ambient UV exposure and sex ( $\mathrm{p}$ for interaction $=0.01$ ) and race $(p=0.01)$ (Table 3$)$. Higher ambient UV exposure was significantly associated with a decreased risk of HCC among males (adjusted IRR 0.83, 95\% CI 0.76, 0.91), but not among females; and among whites (adjusted IRR 0.88, 95\% CI 0.80, 0.96) and Asians, Pacific Islanders, American Indians, and Alaskan Natives (adjusted IRR 0.67, 95\% CI $0.48,0.92)$, but not among blacks. However, the association between UV and HCC risk was consistently inverse across all strata defined by sex and race, although suggestive among females and blacks. The association between UV and HCC risk did not differ according to residential mobility (Table 3). Higher ambient UV exposure was statistically significantly associated with decreased HCC risk when examining exposure lags of (at least) 20 years (UV exposure estimated in 1980; $p=0.04), 15$ years $(1980-1985$; $p<0.01)$, 10 years $(1980-1990 ; p<0.01)$, and 5 years (1980-1995; $p<0.01$ ) (Additional file 1: Table S2). Using Poisson regression with a random intercept for county and scaled Poisson models applying either the Pearson and deviance methods showed similar results.

\section{Discussion}

We observed a statistically significant inverse association between county-level ambient UV exposure and HCC risk in the SEER U.S. population after adjustment for individual-level age at diagnosis, sex, race, and year of diagnosis, SEER registry, and county-level information on health conditions, lifestyle, socioeconomic, and environmental factors. This association was modified by sex and race, where an inverse association was more apparent among male, whites, and Asians, Pacific Islanders, American Indians, and Alaskan Natives. To the best of 
Table 1 Characteristics of HCC cases and comparison of counties where cases lived vs. all U.S. counties

\begin{tabular}{|c|c|c|}
\hline & Cases $(n=56,245)$ & U.S. counties ${ }^{a}$ \\
\hline Age at diagnosis (mean $\pm \mathrm{SD}$ ) & $62.4 \pm 11.6$ & \\
\hline \multicolumn{3}{|l|}{$\operatorname{Sex}(n[\%])$} \\
\hline Male & $43,357(77.1)$ & \\
\hline Female & $12,888(22.9)$ & \\
\hline \multicolumn{3}{|l|}{ Race $(\mathrm{n}[\%])$} \\
\hline White & $38,546(68.5)$ & \\
\hline Black & $7737(13.8)$ & \\
\hline Asian or Pacific Islander & $9305(16.5)$ & \\
\hline $\begin{array}{l}\text { American Indian or } \\
\text { Alaskan Native }\end{array}$ & $657(1.2)$ & \\
\hline \multicolumn{3}{|l|}{$\begin{array}{l}\text { Region of residence at } \\
\text { diagnosis }\end{array}$} \\
\hline Northeast & $7596(13.5)$ & \\
\hline South & 9995 (17.8) & \\
\hline Midwest & $4084(7.3)$ & \\
\hline West & $34,570(61.5)$ & \\
\hline \multicolumn{3}{|l|}{ Year of diagnosis (n[\%]) } \\
\hline $2000-2007$ & $23,589(41.9)$ & \\
\hline 2008-2014 & $32,656(58.1)$ & \\
\hline $\begin{array}{l}\text { Average UV from } 1980 \text { to } 1999 \\
\left(\mathrm{~mW} / \mathrm{m}^{2}\right)(\text { mean } \pm \mathrm{SD})^{\mathrm{b}}\end{array}$ & $214.4 \pm 36.1$ & $193.1 \pm 24.2$ \\
\hline Heavy alcohol consumption (mean \pm SD) $)^{b}$ & $8.3 \pm 2.2$ & $6.4 \pm 2.1$ \\
\hline Smoking status (mean $\pm \mathrm{SD})^{\mathrm{b}}$ & $23.9 \pm 4.8$ & $26.7 \pm 3.6$ \\
\hline $\begin{array}{l}\text { Any physical activity } \\
(\text { mean } \pm \mathrm{SD})^{\mathrm{b}, c}\end{array}$ & $76.9 \pm 5.8$ & $71.7 \pm 6.1$ \\
\hline Obesity $(\text { mean } \pm S D)^{b, c}$ & $25.7 \pm 4.1$ & $30.0 \pm 3.9$ \\
\hline Diabetes $(\text { mean } \pm \mathrm{SD})^{\mathrm{b}}$ & $11.4 \pm 1.7$ & $10.9 \pm 1.9$ \\
\hline $\begin{array}{l}\text { Median household income } \\
(\$ 10,000)(\text { mean } \pm S D)^{b}\end{array}$ & $47.1 \pm 11.1$ & $35.3 \pm 8.8$ \\
\hline Bachelor's degree or higher (mean $\pm S D)^{b}$ & $26.1 \pm 9.2$ & $16.5 \pm 7.8$ \\
\hline Unemployed $(\text { mean } \pm \mathrm{SD})^{\mathrm{b}}$ & $6.5 \pm 2.3$ & $5.8 \pm 2.7$ \\
\hline \multicolumn{3}{|l|}{ Urbanicity $(\mathrm{n}[\%])^{\mathrm{b}}$} \\
\hline Rural & $460(0.8)$ & 21.1 \\
\hline Urban & $55,785(99.2)$ & 78.8 \\
\hline $\mathrm{PM}_{2.5}\left(\mu \mathrm{g} / \mathrm{m}^{3}\right)(\text { mean } \pm \mathrm{SD})^{\mathrm{b}}$ & $14.6 \pm 3.1$ & $12.6 \pm 3.2$ \\
\hline $\begin{array}{l}\text { Occupation in agriculture, forestry, fishing, hunting, } \\
\text { or construction (mean } \pm S D)^{b}\end{array}$ & $13.8 \pm 8.4$ & $13.9 \pm 3.8$ \\
\hline \multicolumn{3}{|l|}{$\begin{array}{l}\text { Drug poisoning mortality rate } \\
\text { (per } 100,000)(\mathrm{n}[\%])^{\mathrm{b}}\end{array}$} \\
\hline $0-2$ & $617(1.1)$ & 23.1 \\
\hline $2.1-10$ & $50,429(89.7)$ & 70.4 \\
\hline$\geq 10.1$ & $5199(9.2)$ & 6.5 \\
\hline Foreign born $(\text { mean } \pm S D)^{b}$ & $17.9 \pm 12.1$ & $3.4 \pm 7.8$ \\
\hline
\end{tabular}

HCC hepatocellular carcinoma, $P M_{2.5}$ particulate matter $<2.5 \mu \mathrm{m}, S D$ standard deviation, SEER Surveillance, Epidemiology, and End Results, UV ultraviolet radiation ${ }^{a}$ Characteristics of the 3108 counties across the contiguous U.S. (including Washington, D.C.)

${ }^{b}$ County-level information based on the county at diagnosis for cases from SEER

${ }^{\mathrm{c} S e x}$-specific any physical activity and obesity prevalence rates were averaged to estimate a total prevalence 


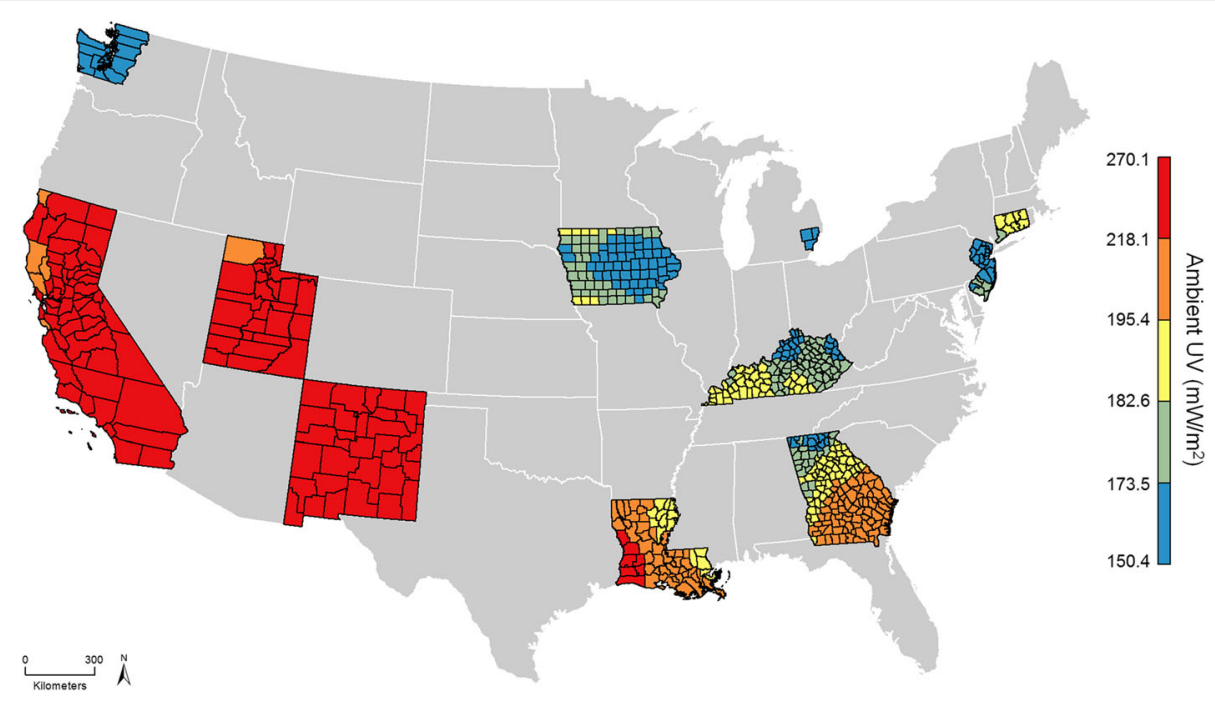

Fig. 1 Ambient UV exposure from 1980 to 1999 by quintiles across 607 counties (16 SEER registries)

our knowledge, this is the first epidemiologic study examining ambient UV exposure and HCC risk.

HCC incidence has been dramatically increasing in the U.S. [59]. Liver cancer is a priority area for cancer prevention and control efforts worldwide [60]. HCC is often asymptomatic until diagnosed at a late stage and is associated with a low 5-year relative survival rate below $12 \%$ [61]. Yet more than one third of HCC cases in the U.S. are not explained by known risk factors such as chronic infection with $\mathrm{HCV}$ or $\mathrm{HBV}$, alcohol consumption, diabetes, and obesity [8]. Recent evidence suggests that vitamin D is a modifiable factor that may influence the risk of developing HCC. Vitamin D suppresses hepatic stellate cell (HSC) proliferation [62], which when activated, facilitates excessive collagen accumulation - the hallmark of liver fibrosis. Activation of VDRs in HSCs strongly antagonizes TGF- $\beta$ signaling, the most potent pro-fibrogenic pathway in the liver [63, 64]. Vitamin D also exhibits cytostatic and apoptotic effects in hepatic malignant cells that express VDR [65] and inhibits hepatic chromosomal aberrations and DNA breaks [66]. Several epidemiologic studies have examined vitamin $\mathrm{D}$ from diet or serum and primary liver cancer risk and have shown mixed results. In a prospective case-control study of 138 HCC cases nested within the
European Prospective Investigation into Cancer and Nutrition (EPIC) cohort, higher serum 25(OH)D levels were associated with a statistically significant decreased risk of HCC (IRR 0.51, 95\% CI 0.26, 0.99) after adjusting for age, sex, study center, date and time of blood collection, fasting status, smoking, BMI, alcohol consumption, and coffee consumption [17]. Vitamin D was assessed using a serum measurement at baseline occurring an average of 6 years before diagnosis. A second nested case-control study in EPIC (191 HCC cases) showed a statistically significant positive association between baseline dietary vitamin $\mathrm{D}$ intake (from dairy sources) and risk of HCC (HR 1.90, 95\% CI 1.19, 3.05) after adjusting for age, sex, study center, total energy intake, alcohol consumption, physical activity, BMI, smoking, and diabetes [16]. Higher intake of dairy foods is associated with higher levels of circulating insulin-like growth factor I (IGF-I), which have been hypothesized to promote hepatocarcinogenesis [67]. In both EPIC studies, similar results were observed after adjusting for $\mathrm{HBV} / \mathrm{HCV}$ infection. A nested case-control study in the Linxian Nutrition Intervention Trials in China showed no association between baseline serum $25(\mathrm{OH}) \mathrm{D}$ and risk of primary liver cancer [18], although there was a statistically significant interaction between vitamin D and calcium. An inverse

Table 2 Association between ambient UV and HCC incidence (SEER 2000-2014)

\begin{tabular}{|c|c|c|c|c|c|}
\hline UV exposure & Cases $(n)$ & $\begin{array}{l}\text { Basic }^{a} \\
\text { IRR (95\% Cl) }\end{array}$ & $p$ & $\begin{array}{l}\text { Fully adjusted } \\
\text { IRR }(95 \% \mathrm{Cl})\end{array}$ & $p$ \\
\hline$\overline{U V}\left(\right.$ per IQR increase) ${ }^{c}$ & 56,245 & $0.90(0.81,0.99)$ & 0.04 & $0.83(0.77,0.90)$ & $<0.01$ \\
\hline
\end{tabular}

Cl confidence interval, HCC hepatocellular carcinoma, IQR interquartile range, IRR incidence rate ratio, SEER Surveillance, Epidemiology, and End Results, UV ultraviolet radiation

aAdjusted for age at diagnosis, sex, race, year of diagnosis, and SEER registry

${ }^{\mathrm{b}}$ Additionally adjusted for the following county-level variables: prevalence of heavy alcohol consumption, smoking, obesity, diabetes; median household income; percentage unemployed; urbanicity; $\mathrm{PM}_{2.5}$

${ }^{\mathrm{C}} \mathrm{QR}$ corresponds to $32.4 \mathrm{~mW} / \mathrm{m}^{2}$ 
Table 3 Association between ambient UV and HCC incidence stratified by sex, race, and residential mobility

\begin{tabular}{llll}
\hline UV exposure (per IQR increase) $^{\mathrm{a}}$ & Cases $(n)$ & $\begin{array}{l}\text { Fully adjusted }^{\mathrm{b}} \\
\text { IRR }(95 \% \mathrm{Cl})\end{array}$ & $p$ int. \\
\hline Sex & & & 0.01 \\
$\quad$ Male & 43,357 & $0.83(0.76,0.91)$ & \\
$\quad$ Female & 12,888 & $0.95(0.85,1.07)$ & \\
Race & & & 0.01 \\
$\quad$ White & 38,546 & $0.88(0.80,0.96)$ & \\
$\quad$ Black & 7737 & $0.85(0.57,1.26)$ & \\
$\quad$ Asian, Pacific Islander, & 9962 & $0.67(0.48,0.92)$ & \\
$\quad$ American Indian, Alaskan & & & \\
$\quad$ Native & & & 0.86 \\
Residential mobility & & & \\
$\quad$ Non-movers & 31,039 & $0.78(0.69,0.88)$ & \\
Movers & 25,206 & $0.88(0.79,0.99)$ & \\
\hline
\end{tabular}

Cl confidence interval, HCC hepatocellular carcinoma, IQR interquartile range, IRR incidence rate ratio, $U V$ ultraviolet radiation

${ }^{\mathrm{a}} \mathrm{OQR}$ corresponds to $32.4 \mathrm{~mW} / \mathrm{m}^{2}$

${ }^{\mathrm{b}}$ Adjusted for age at diagnosis, sex, race, year of diagnosis, SEER registry, and the following county-level variables: prevalence of heavy alcohol consumption, smoking, obesity, diabetes; median household income; percentage unemployed; urbanicity; $\mathrm{PM}_{2.5}$

${ }^{c}$ Non-movers were defined as those who resided in a county where $\geq 51.9 \%$ (20th percentile) of the population stayed in the same home (no migration). Movers resided in a county where $<51.9 \%$ of the population stayed in the same home

association was observed among those with higher serum calcium concentrations; vitamin D signaling may be attenuated by low calcium levels [68]. HCC and other histological subtypes of liver cancer were included in this study, which might have masked the association due to a potential lack of impact of vitamin D on non-HCC liver cancer [69]. Further, the Linxian study population was characterized by a low and narrow range of vitamin D exposure, limiting generalizability and statistical power to detect an association. There was no strong evidence of confounding by the factors evaluated in these studies for the association between vitamin D and liver cancer [16-18]. Although these studies provide inconsistent results regarding the relationship between vitamin D and liver cancer risk in Europe and China, this present study provides evidence in support of sunlight exposure, the major source of vitamin $\mathrm{D}$ from UV-B, and HCC risk. For a given individual, the chronic and constant exposure to UV-B may provide a steady source of vitamin $D$, which may complement the measurement of serum vitamin D reflecting acute exposures in previous studies [17-19].

We examined the association between ambient UV exposure and HCC risk using information from populationbased cancer registries across the U.S. We observed a statistically significant dose-response relationship with increasing ambient UV exposure and decreasing HCC risk. Results were adjusted for many established HCC risk factors such as individual-level age, sex, and race, as well as county-level information on heavy alcohol consumption, smoking, obesity, diabetes, and socioeconomic and environmental factors. We adjusted for county-level ambient $\mathrm{PM}_{2.5}$ air pollution, an environmental exposure that has been shown to potentially increase $\mathrm{HCC}$ risk [51-55]. In our analysis, $\mathrm{PM}_{2.5}$ was the strongest confounder in the relationship between UV and HCC risk; its adjustment strengthened the observed inverse association. It is known that UV and $\mathrm{PM}_{2.5}$ are negatively associated with each other, where $\mathrm{PM}_{2.5}$ can absorb and/or scatter UV, thus impacting the amount of UV reaching the Earth's surface [70]. Location-based ambient UV exposure was objectively estimated through linking the SEER county with a high spatial- and temporal-resolution UV model using GIS. Average annual July erythemal UV was estimated, which has been used in previous cancer epidemiologic studies [24, 25] and is relevant to studying chronic diseases in considering long-term average exposure. Although the mechanisms underlying the potential effect of vitamin D on hepatocarcinogenesis may differ from those of other known risk factors, there has been an observed 20-year latency period for some liver cancer risk factors [71]. We explored potential latency periods by examining exposure lags and observed significant inverse associations between ambient UV exposure and HCC risk when estimating exposure at least $5,10,15$, and 20 years before diagnosis.

Ambient UV exposure measures have been predictive of cancer risk, for example demonstrating adverse associations with skin cancer risk where the underlying mechanism is DNA damage as well as inverse associations with colon and other cancers where the mechanism is related to vitamin D protection [20-27, 72]. Although ambient UV is an indirect measure, UV-B sunlight exposure is considered an important predictor of vitamin D status in the population [73]. Sunlight exposure, in addition to diet, are considered to be reasonable measures for long-term vitamin D status [19]. Further, sunlight exposure accounts for approximately $90 \%$ of circulating levels of vitamin D [19]. Baseline serum $25(\mathrm{OH}) \mathrm{D}$ reflects short-term vitamin $\mathrm{D}$ status rather than long-term vitamin $\mathrm{D}$ exposure, the latter being more relevant to carcinogenesis. Although an intraclass correlation coefficient (ICC) of 0.72 has been observed for plasma $25(\mathrm{OH}) \mathrm{D}$ levels measured over $2-3$ years, the ICC decreased over time to 0.50 (95\% CI 0.43, 0.57) over 10-11 years, demonstrating increasing within-person variability [74]. Other studies have reported ICCs ranging between 0.42 and 0.72 over $2-14$ years [75-78]. Serum measurements are also subject to intra-individual variation related to residence in high UV-B areas and changes in lifestyle practices (e.g., sunscreen use) over 
time [19]. Ambient UV represents an informative measure for studies seeking to examine the role of vitamin D in human health outcomes, and can be used in combination with direct assessments of vitamin D, such as using serum and diet, to comprehensively capture vitamin $\mathrm{D}$ status.

There were statistically significant interactions between ambient UV exposure and sex and race. A statistically significant inverse association was observed among males, while no association was observed among females. These results may be explained by the smaller sample size of females and/or vitamin D deficiency being more common among females compared to males, partially attributed to sex-specific differences in outdoor activities, clothing for skin coverage, seeking shade, and sunscreen use $[79,80]$. Results were similar after adjustment for sex-specific county-level outdoor occupation. An inverse association was observed among whites and Asians, Pacific Islanders, American Indians, and Alaskan Natives but not blacks, consistent with how darker skin, associated with increased melanin, absorbs between 50 and $75 \%$ of UV, thus reducing vitamin D production in the skin and manifesting in higher rates of vitamin D deficiency among non-whites [81-83]. However, results among blacks were suggestively inverse and the sample sizes for blacks as well as Asians, Pacific Islanders, American Indians, and Alaskan Natives were smaller compared to whites. Racial and ethnic differences in dietary intake may have also contributed to these results [84]. Differential patterns of residential mobility may also exist according to sex and race.

Limitations of this study include absence of information on personal UV exposure and potential exposure misclassification associated with using the county of residence (at diagnosis among cases). Study results may be subject to the ecological fallacy, where the association between area-level ambient UV, as a moderate proxy for vitamin $\mathrm{D}$ status, and HCC may not reflect the individual-level association between vitamin $\mathrm{D}$ and HCC. For example, although previous studies have demonstrated an inverse association between area-level UV and breast cancer incidence, individual-level studies of personal sunlight exposure and serum vitamin $\mathrm{D}$ have not been able to consistently replicate these findings [85, 86]. However, both ecological and individual-level studies examining ambient UV and serum vitamin D have demonstrated inverse associations with colorectal cancer risk [20, 24, 87]. Additional studies examining individual-level exposure of vitamin D and HCC risk are needed. We used a high-resolution spatiotemporal UV model validated against ground truth UV monitoring data [35] to estimate exposure and exposure was assessed similarly across all counties in the study. Further, counties have been used in previous epidemiologic studies as geographic variables capturing activity space, or the local areas within which people move or travel during the course of their daily activities interacting with their environment $[88,89]$. We estimated UV exposure beginning in 1980 and assumed that cases did not move over the study time period. Although we did not have information on residential history, cases lived in counties where a large proportion of individuals did not migrate; an average of $58 \%$ of county residents stayed in the same home between 1995 and 2000 (10th percentile was 48\%). Further, results were similar after stratifying by county residential mobility. Residual confounding due to lack of information on individual-level risk factors for HCC, including alcohol consumption and obesity, is a limitation. However, we were able to adjust for county-level information on known and suspected HCC risk factors, including heavy alcohol consumption, smoking, obesity, diabetes, socioeconomic factors, urbanicity, and $\mathrm{PM}_{2.5}$. We also evaluated potential confounding by county-level outdoor occupation (affects UV exposure levels), drug poisoning mortality (proxy for $\mathrm{HCV}$ prevalence), and percentage of foreign-born individuals (proxy for HBV prevalence), none of which substantially changed the effect estimate for the association between ambient UV and HCC. In particular, although the percentage of foreign-born individuals was higher in counties in which HCC cases resided compared to all counties in the U.S., there was a weak positive association between percentage of foreign-born individuals and county-level ambient UV levels. Further, HBV and HCV, the latter being the major risk factor for liver cancer in the U.S., have not been associated with vitamin $\mathrm{D}$ in several previous studies, suggesting that $\mathrm{HBV}$ and $\mathrm{HCV}$ are not likely to be strong confounders of the association [16-18]. Obesity is the major risk factor for non-HBV/HCV-related HCC in the U.S. Lower vitamin D levels are associated with obesity [90], however it is unclear if ambient UV is associated with obesity, although obesity prevalence is higher in the Southern U.S. where UV levels are high [91]. We adjusted for county-level obesity, although residual confounding remains an issue. We also lacked information on individual-level sun exposure and protection, including sun reaction, sunscreen use, tanning booth use, and time spent outdoors, although we did consider sexspecific county-level percentage of the population employed in outdoor occupations in our analysis (results did not change after adjustment). We did not have information on dietary and supplemental vitamin D intake. Strengths of our study include the large sample size of HCC cases and objective location-based exposure assessment utilizing a high-resolution spatially- and temporallyvarying UV model created using information regarding known predictors of UV including ozone, aerosol optical depth, and cloud cover. The counties included in the 
study area span the contiguous U.S. and are characterized by a wide range of UV values. Using information from various objective data sources including SEER, U.S. Census Bureau, IHME, and EPA, we were able to evaluate potential confounding and effect modification by many different variables including age, sex, and race.

\section{Conclusions}

Higher ambient UV exposure was associated with a statistically significant reduced risk of HCC in the U.S. The incidence rate of $\mathrm{HCC}$ has increased in many parts of the world including the U.S. UV exposure, a major source of vitamin $\mathrm{D}$ production, may be a potential modifiable risk factor for HCC. Additional studies examining the association between individual-level measures of vitamin D in blood or from other sources, including diet and dietary supplements, and HCC risk should be conducted.

\section{Additional file}

Additional file 1: Modeling the association between ambient UV and HCC incidence and analyses using exposure lags of 5-20 years. (DOCX $21 \mathrm{~kb}$ )

\section{Abbreviations \\ 25(OH)D: 25-hydroxyvitamin D; BMl: Body mass index; Cl: Confidence interval; EPA: Environmental Protection Agency; EPIC: European Prospective Investigation into Cancer and Nutrition; FIPS: Federal Information Processing Standard; GIS: Geographic information system; HBV: Hepatitis B virus; HCC: Hepatocellular carcinoma; HCV: Hepatitis C virus; HSC: Hepatic stellate cell; IARC: International Agency for Research on Cancer; ICC: Intraclass correlation coefficient; ICD-10: International Classification of Diseases, Tenth Revision; ICD-O-3: International Classification of Diseases for Oncology, Third Edition; IGF-I: Insulin-like growth factor I; IHME: Institute for Health Metrics and Evaluation; IQR: Interquartile range; IRB: Institutional Review Board; IRR: Incidence rate ratio; NAD83: North American Datum of 1983; NASA: National Aeronautics and Space Administration; OMl: Ozone Monitoring Instrument; $\mathrm{PM}_{2.5}$ : particulate matter $<2.5 \mu \mathrm{m}$ in diameter; SD: Standard deviation; SEER: Surveillance, Epidemiology, and End Results; TGF- $\beta$ : Transforming growth factor beta; TOMS: Total Ozone Mapping Spectrometer; U.S.: United States; USGS: U.S. Geological Survey; UV: Ultraviolet radiation; UV-A: Ultraviolet A radiation; UV-B: Ultraviolet B radiation; VDR: Vitamin D receptor}

\section{Acknowledgements}

The authors would like to acknowledge the NCI SEER program, IHME, EPA, U.S. Census Bureau, Minnesota Population Center, and Centers for Disease Control and Prevention for providing the publicly available data used in this study.

\section{Funding}

This work was supported by the National Institutes of Health $(\mathrm{NIH})$ National Cancer Institute (NCI) Training Program in Cancer Epidemiology (T32 CA009001).

\section{Availability of data and materials}

All data and materials are publicly available. The code from the current study is available from the corresponding author on reasonable request.

\section{Authors' contributions}

TV was responsible for the inception of this study, data acquisition, execution of the analyses, interpretation of the results, and production of the manuscript. KAB, JMY, RMT, JEH, and FL contributed to the analyses, interpretation of results, and provided revisions to the final manuscript. All authors read and approved the final manuscript.

\section{Ethics approval and consent to participate}

To protect patient confidentiality, the SEER database does not include personal identifiers. This study was exempt from Institutional Review Board (IRB) review.

\section{Consent for publication \\ Not applicable}

\section{Competing interests}

The authors declare that they have no competing interests.

\section{Publisher's Note}

Springer Nature remains neutral with regard to jurisdictional claims in published maps and institutional affiliations.

\section{Author details}

'Department of Epidemiology, Harvard T.H. Chan School of Public Health, Boston, MA, USA. ${ }^{2}$ Channing Division of Network Medicine, Department of Medicine, Brigham and Women's Hospital and Harvard Medical School, Boston, MA, USA. ${ }^{3}$ Slone Epidemiology Center at Boston University, Boston, MA, USA. ${ }^{4}$ Division of Cancer Control and Population Sciences, University of Pittsburgh Cancer Institute, Pittsburgh, PA, USA. ${ }^{5}$ Department of Epidemiology, Graduate School of Public Health, University of Pittsburgh, Pittsburgh, PA, USA. 'Exposure, Epidemiology, and Risk Program, Department of Environmental Health, Harvard T.H. Chan School of Public Health, Boston, MA, USA.

Received: 15 May 2017 Accepted: 14 August 2017

Published online: 18 August 2017

\section{References}

1. Carr Bl. Hepatocellular carcinoma: diagnosis and treatment. Third ed. Cham: Springer International Publishing; 2016.

2. El-Serag HB, Rudolph KL. Hepatocellular carcinoma: epidemiology and molecular carcinogenesis. Gastroenterol. 2007;132(7):2557-76.

3. McGlynn KA, Petrick JL, London WT. Global epidemiology of hepatocellular carcinoma: an emphasis on demographic and regional variability. Clin Liver Dis. 2015;19(2):223-38.

4. Petrick JL, Freedman ND, Graubard BI, Sahasrabuddhe W, Lai GY, Alavanja MC, Beane-Freeman LE, Boggs DA, Buring JE, Chan AT. Coffee consumption and risk of hepatocellular carcinoma and intrahepatic cholangiocarcinoma by sex: the Liver Cancer Pooling Project. Cancer Epidemiol Biomark Prev. 2015;24(9):1398-406.

5. Sing MF, Yang W-S, Gao S, Gao J, Xiang Y-B. Epidemiological studies of the association between tea drinking and primary liver cancer: a meta-analysis. Eur J Cancer Prev. 2011;20(3):157-65.

6. Behrens G, Matthews CE, Moore SC, Freedman ND, McGlynn KA, Everhart JE, Hollenbeck AR, Leitzmann MF. The association between frequency of vigorous physical activity and hepatobiliary cancers in the NIH-AARP Diet and Health Study. Eur J Epidemiol. 2013;28(1):55-66.

7. Petrick JL, Braunlin M, Laversanne M, Valery PC, Bray F, McGlynn KA. International trends in liver cancer incidence, overall and by histologic subtype, 1978-2007. Int J Cancer. 2016;139(7):1534-45.

8. Makarova-Rusher OV, Altekruse SF, McNeel TS, Ulahannan S, Duffy AG, Graubard BI, Greten TF, McGlynn KA. Population attributable fractions of risk factors for hepatocellular carcinoma in the United States. Cancer. 2016; 122(11):1757-65.

9. Deeb KK, Trump DL, Johnson CS. Vitamin D signalling pathways in cancer: potential for anticancer therapeutics. Nat Rev Cancer. 2007:7(9):684-700.

10. Grant WB, Holick MF. Benefits and requirements of vitamin D for optimal health: a review. Altern Med Rev. 2005;10(2):94-111.

11. Holick MF. Vitamin D deficiency. N Engl J Med. 2007;357(3):266-81.

12. Vanoirbeek E, Krishnan A, Eelen G, Verlinden L, Bouillon R, Feldman D, Verstuyf A. The anti-cancer and anti-inflammatory actions of 1, $25(\mathrm{OH}) 2 \mathrm{D}$ 3. Best Pract Res Clin Endocrinol Metab. 2011;25(4):593-604.

13. Chiang JY. Bile acids: regulation of synthesis. J Lipid Res. 2009;50(10): 1955-66.

14. Ogura M, Nishida S, Ishizawa M, Sakurai K, Shimizu M, Matsuo S, Amano S, Uno S, Makishima M. Vitamin D3 modulates the expression of bile acid regulatory genes and represses inflammation in bile duct-ligated mice. J Pharmacol Exp Ther. 2009;328(2):564-70. 
15. Schmidt DR, Holmstrom SR, Tacer KF, Bookout AL, Kliewer SA, Mangelsdorf DJ. Regulation of bile acid synthesis by fat-soluble vitamins A and D. J Biol Chem. 2010;285(19):14486-94.

16. Duarte-Salles T, Fedirko V, Stepien M, Trichopoulou A, Bamia C, Lagiou P Lukanova A, Trepo E, Overvad K, Tjønneland A. Dairy products and risk of hepatocellular carcinoma: the European Prospective Investigation into Cancer and Nutrition. Int J Cancer. 2014;135(7):1662-72.

17. Fedirko V, Duarte-Salles T, Bamia C, Trichopoulou A, Aleksandrova K, Trichopoulos D, Trepo E, Tjønneland A, Olsen A, Overvad K. Prediagnostic circulating vitamin D levels and risk of hepatocellular carcinoma in European populations: a nested case-control study. Hepatology. 2014;60(4):1222-30.

18. Wang J, Abnet C, Chen W, Dawsey S, Fan J, Yin L, Yin J, Major J, Taylor P, Qiao Y. Association between serum $25(\mathrm{OH})$ vitamin D, incident liver cancer and chronic liver disease mortality in the Linxian Nutrition Intervention Trials: a nested case-control study. Br J Cancer. 2013;109(7):1997-2004.

19. Millen AE, Bodnar LM. Vitamin D assessment in population-based studies: a review of the issues. Am J Clin Nutr. 2008:87(4):1102S-5S.

20. Boscoe FP, Schymura MJ. Solar ultraviolet-B exposure and cancer incidence and mortality in the United States, 1993-2002. BMC Cancer. 2006;6(1):264.

21. Chen W, Clements M, Rahman B, Zhang S, Qiao Y, Armstrong BK. Relationship between cancer mortality/incidence and ambient ultraviolet B irradiance in China. Cancer Causes Control. 2010;21(10):1701-9.

22. Freedman DM, Rajaraman P, Fuhrman B, Hoffbeck R, Alexander BH. Sunlight, hormone replacement status and colorectal cancer risk in postmenopausal women. Int J Cancer. 2010;126(8):1997-2001.

23. Hughes AM, Lucas RM, Ponsonby AL, Chapman C, Coulthard A, Dear K, Dwyer T, Kilpatrick TJ, McMichael AJ, Pender MP. The role of latitude, ultraviolet radiation exposure and vitamin $D$ in childhood asthma and hayfever: an Australian multicenter study. Pediatr Allergy Immunol. 2011; 22(3):327-33.

24. Lin SW, Wheeler DC, Park Y, Cahoon EK, Hollenbeck AR, Freedman DM, Abnet CC. Prospective study of ultraviolet radiation exposure and risk of cancer in the United States. Int J Cancer. 2012;131(6):E1015-23.

25. Lin S-W, Wheeler DC, Park Y, Spriggs M, Hollenbeck AR, Freedman DM, Abnet CC. Prospective study of ultraviolet radiation exposure and mortality risk in the United States. Am J Epidemiol. 2013;178(4):521-33.

26. Sloka S, Grant M, Newhook LA. The geospatial relation between UV solar radiation and type 1 diabetes in Newfoundland. Acta Diabetol. 2010;47(1):73-8.

27. Chang ET, Canchola AJ, Cockburn M, Lu Y, Wang SS, Bernstein L, Clarke CA, Horn-Ross PL. Adulthood residential ultraviolet radiation, sun sensitivity, dietary vitamin D, and risk of lymphoid malignancies in the California Teachers Study. Blood. 2011;118(6):1591-9.

28. National Cancer Institute. Surveillance, Epidemiology, and End Results Program. https://seer.cancer.gov/. Accessed 3 Apr 2017.

29. Surveillance $E$, and End Results (SEER) Program (www.seer.cancer.gov) SEER*Stat Database: Incidence - SEER 18 Regs Research Data + Hurricane Katrina Impacted Louisiana Cases, Nov 2016 Sub (1973-2014 varying) - Linked To County Attributes - Total U.S., 1969-2015 Counties, National Cancer Institute, DCCPS, Surveillance Research Program, Surveillance Systems Branch, released April 2017, based on the November 2016 submission.

30. Fritz A, Percy C, Shanmugaratnam K, Sobin L, Parkin DM, Whelan S. International Classification of Diseases for Oncology: ICD-O. 3rd ed. Geneva: World Health Organization; 2000

31. Davila JA, Morgan RO, Shaib Y, McGlynn KA, El-Serag HB. Diabetes increases the risk of hepatocellular carcinoma in the United States: a population based case control study. Gut. 2005;54(4):533-9.

32. VoPham T, Brooks MM, Yuan JM, Talbott EO, Ruddell D, Hart JE, Chang CC, Weissfeld $J$. Pesticide exposure and hepatocellular carcinoma risk: a casecontrol study using a geographic information system (GIS) to link SEERMedicare and California pesticide data. Environ Res. 2015;143(Pt A):68-82.

33. Bowen EM, Pfeiffer RM, Linet MS, Liu WT, Weisenburger DD, Freedman DM, Cahoon EK. Relationship between ambient ultraviolet radiation and Hodgkin lymphoma subtypes in the United States. Br J Cancer. 2016;114(7): 826-31.

34. Cahoon EK, Pfeiffer RM, Wheeler DC, Arhancet J, Lin SW, Alexander BH, Linet MS, Freedman DM. Relationship between ambient ultraviolet radiation and non-Hodgkin lymphoma subtypes: a US population-based study of racial and ethnic groups. Int J Cancer. 2015;136(5):E432-41.

35. VoPham T, Hart JE, Bertrand KA, Sun Z, Tamimi RM, Laden F. Spatiotemporal exposure modeling of ambient erythemal ultraviolet radiation. Environ Health. 2016;15(1):111.
36. McKinlay A, Diffey B. A reference action spectrum for ultraviolet induced erythema in human skin. CIE J. 1987;6(1):17-22.

37. NASA. Erythemal Exposure Data Product. http://ozoneaq.gsfc.nasa.gov/ media/docs/erynotes.pdf. Accessed 1 Jun 2015.

38. Grant WB. An estimate of premature cancer mortality in the US due to inadequate doses of solar ultraviolet-B radiation. Cancer. 2002;94(6):1867-75.

39. Minnesota Population Center. National Historical Geographic Information System: Version 11.0 [Database]. http://doi.org/10.18128/D050.V11.0. Accessed 15 Feb 2017

40. National Cancer Institute. Surveillance, Epidemiology, and End Results: County Attributes. https:/seer.cancer.gov/seerstat/variables/countyattribs/. Accessed 3 Apr 2017.

41. Institute for Health Metrics and Evaluation. United States Alcohol Use Prevalence by County 2002-2012. Seattle: Institute for Health Metrics and Evaluation; 2015.

42. Dwyer-Lindgren L, Flaxman AD, Ng M, Hansen GM, Murray CJ, Mokdad AH. Drinking patterns in US counties from 2002 to 2012. Am J Public Health 2015;105(6):1120-7.

43. Institute for Health Metrics and Evaluation. Diagnosed and Undiagnosed Diabetes Prevalence by County in the U.S., 1999-2012. Seattle: Institute for Health Metrics and Evaluation; 2016.

44. Dwyer-Lindgren $L$, Mackenbach JP, van Lenthe FJ, Flaxman AD, Mokdad AH. Diagnosed and undiagnosed diabetes prevalence by County in the US, 1999-2012. Diabetes Care. 2016;39(9):1556-62.

45. Dwyer-Lindgren L, Freedman G, Engell RE, Fleming TD, Lim SS, Murray CJ, Mokdad AH. Prevalence of physical activity and obesity in US counties, 2001-2011: a road map for action. Popul Health Metr. 2013;11(1):7.

46. Dwyer-Lindgren L, Mokdad AH, Srebotnjak T, Flaxman AD, Hansen GM, Murray CJ. Cigarette smoking prevalence in US counties: 1996-2012. Popul Health Metr. 2014;12(1):5.

47. Rossen LM, Khan D, Warner M. Trends and geographic patterns in drugpoisoning death rates in the US, 1999-2009. Am J Prev Med. 2013;45(6):e19-25.

48. Centers for Disease Control and Prevention. Drug Poisoning Mortality: United States, 1999-2014. https://blogs.cdc.gov/nchs-data-visualization/ drug-poisoning-mortality/. Accessed 23 Feb 2017.

49. Centers for Disease Control and Prevention. Hepatitis C FAQs for Health Professionals. https://www.cdc.gov/hepatitis/hcv/hcvfaq.htm\#section2. Accessed 1 Apr 2017.

50. Rudd RA, Aleshire N, Zibbell JE, Matthew GR. Increases in drug and opioid overdose deaths_United States, 2000-2014. Am J Transplant. 2016;16(4): 1323-7.

51. International Agency for Research on Cancer. IARC monographs on the evaluation of carcinogenic risks to humans: outdoor air pollution. 2016.

52. Kim JW, Park S, Lim CW, Lee K, Kim B. The role of air pollutants in initiating liver disease. Toxicol Res. 2014;30(2):65.

53. Zheng Z, Zhang X, Wang J, Dandekar A, Kim H, Qiu Y, Xu X, Cui Y, Wang A, Chen LC. Exposure to fine airborne particulate matters induces hepatic fibrosis in murine models. J Hepatol. 2015;63(6):1397-404.

54. Pan W-C, Wu C-D, Chen M-J, Huang Y-T, Chen C-J, Su H-J, Yang H-I. Fine particle pollution, alanine transaminase, and liver cancer: a Taiwanese prospective cohort study (REVEAL-HBV). J Natl Cancer Inst. 2016;108(3): djv341.

55. Pedersen M, Andersen ZJ, Stafoggia M, Weinmayr G, Galassi C, Sørensen M, Eriksen KT, Tjønneland A, Loft S, Jaensch A. Ambient air pollution and primary liver cancer incidence in four European cohorts within the ESCAPE project. Environ Res. 2017;154:226-33.

56. Roberts JD, Voss JD, Knight B. The association of ambient air pollution and physical inactivity in the United States. PLoS One. 2014;9(3):e90143.

57. U.S. Census Bureau. Census Regions and Divisions of the United States. https://www2.census.gov/geo/pdfs/maps-data/maps/reference/us_regdiv. pdf. Accessed 15 Apr 2017

58. Lee J-H, Han G, Fulp W, Giuliano A. Analysis of overdispersed count data: application to the Human Papillomavirus Infection in Men (HIM) Study. Epidemiol Infect. 2012:140(06):1087-94.

59. Ryerson AB, Eheman CR, Altekruse SF, Ward JW, Jemal A, Sherman RL, Henley SJ, Holtzman D, Lake A, Noone AM. Annual Report to the Nation on the Status of Cancer, 1975-2012, featuring the increasing incidence of liver cancer. Cancer. 2016;122(9):1312-37.

60. Hashim D, Boffetta P, La Vecchia C, Rota M, Bertuccio P, Malvezzi M, Negri E. The global decrease in cancer mortality: trends and disparities. Ann Oncol. 2016;27(5):926-33. 
61. El-Serag HB. Hepatocellular carcinoma. N Engl J Med. 2011;365(12):1118-27.

62. Abramovitch S, Dahan-Bachar L, Sharvit E, Weisman Y, Tov AB, Brazowski E, Reif S. Vitamin D inhibits proliferation and profibrotic marker expression in hepatic stellate cells and decreases thioacetamide-induced liver fibrosis in rats. Gut. 2011;60(12):1728-37.

63. Ding N, Liddle C, Evans RM, Downes M. Hepatic actions of vitamin D receptor ligands: a sunshine option for chronic liver disease? Expert Rev Clin Pharmacol. 2013;6(6):597-9.

64. Ding N, Ruth TY, Subramaniam N, Sherman MH, Wilson C, Rao R, Leblanc M, Coulter S, He M, Scott C. A vitamin D receptor/SMAD genomic circuit gates hepatic fibrotic response. Cell. 2013;153(3):601-13.

65. Feldman D, Krishnan AV, Swami S, Giovannucci E, Feldman BJ. The role of vitamin D in reducing cancer risk and progression. Nat Rev Cancer. 2014; 14(5):342-57.

66. Saha B, Bishayee A, Kanjilal N, Chatterjee M. 1a, 25-Dihydroxyvitamin D3 inhibits hepatic chromosomal aberrations, DNA strand breaks and specific DNA adducts during rat hepatocarcinogenesis. Cell Mol Life Sci. 2001;58(8): 1141-9.

67. Schirmacher P, Held W, Yang D, Chisari F, Rustum Y, Rogler C. Reactivation of insulin-like growth factor II during hepatocarcinogenesis in transgenic mice suggests a role in malignant growth. Cancer Res. 1992;52(9):2549-56.

68. Peterlik M, Cross H. Vitamin D and calcium deficits predispose for multiple chronic diseases. Eur J Clin Investig. 2005;35(5):290-304.

69. McGlynn KA, Tarone RE, El-Serag HB. A comparison of trends in the incidence of hepatocellular carcinoma and intrahepatic cholangiocarcinoma in the United States. Cancer Epidemiol Biomark Prev. 2006;15(6):1198-203.

70. Kerr J, Fioletov V. Surface ultraviolet radiation. Atmos-Ocean. 2008;46(1):159-84

71. Ananthakrishnan A, Gogineni V, Saeian K. Epidemiology of primary and secondary liver cancers. In: Seminars in Interventional Radiology: Copyright@ 2006 by Thieme Medical Publishers, Inc., 333 Seventh Avenue, New York, NY 10001, USA. 2006:047-063.

72. Xiang F, Lucas R, Hales S, Neale R. Incidence of nonmelanoma skin cancer in relation to ambient UV radiation in white populations, 1978-2012: empirical relationships. JAMA Dermatol. 2014;150(10):1063-71.

73. Spiro A, Buttriss J. Vitamin D: an overview of vitamin D status and intake in Europe. Nutr Bull. 2014;39(4):322-50

74. Bertrand KA, Giovannucci E, Liu Y, Malspeis S, Eliassen AH, Wu K, Holmes MD, Laden F, Feskanich D. Determinants of plasma 25-hydroxyvitamin D and development of prediction models in three US cohorts. Br J Nutr. 2012; 108(10):1889-96.

75. Jorde R, Sneve M, Hutchinson M, Emaus N, Figenschau Y, Grimnes G. Tracking of serum 25-hydroxyvitamin D levels during 14 years in a population-based study and during 12 months in an intervention study. Am J Epidemiol. 2010;171(8):903-8.

76. Hofmann JN, Yu K, Horst RL, Hayes RB, Purdue MP. Long-term variation in serum 25-hydroxyvitamin D concentration among participants in the Prostate, Lung, Colorectal, and Ovarian Cancer Screening Trial. Cancer Epidemiol Biomark Prev. 2010;19(4):927-31.

77. Giovannucci E, Liu Y, Rimm EB, Hollis BW, Fuchs CS, Stampfer MJ, Willett WC. Prospective study of predictors of vitamin D status and cancer incidence and mortality in men. J Natl Cancer Inst. 2006;98(7):451-9.

78. Kotsopoulos J, Tworoger SS, Campos H, Chung F-L, Clevenger CV, Franke AA, Mantzoros CS, Ricchiuti V, Willett WC, Hankinson SE. Reproducibility of plasma, red blood cell, and urine biomarkers among premenopausal and postmenopausal women from the Nurses' Health Studies. Cancer Epidemiol Biomark Prev. 2010;19(4):938-46.

79. Ginde AA, Liu MC, Camargo CA. Demographic differences and trends of vitamin D insufficiency in the US population, 1988-2004. Arch Intern Med Title. 2009;169(6):626-32.

80. Nair R, Maseeh A. Vitamin D: the "sunshine" vitamin. J Pharmacol Pharmacother. 2012;3(2):118.

81. Brenner $\mathrm{M}$, Hearing VJ. The protective role of melanin against UV damage in human skin. Photochem Photobiol. 2008;84(3):539-49.

82. Harris SS. Vitamin D and african americans. J Nutr. 2006:136(4):1126-9.

83. Mitchell D, Henao M, Finkelstein J, Burnett-Bowie S-A. Prevalence and predictors of vitamin D deficiency in healthy adults. Endocr Pract. 2012; 18(6):914-23.

84. Moore CE, Murphy MM, Holick MF. Vitamin D intakes by children and adults in the United States differ among ethnic groups. J Nutr. 2005;135(10):2478-85.

85. Visvanathan K, Mondul A, Zeleniuch-Jacquotte A, Mukhtar TK, Smith-Warner SA, Ziegler RG. Abstract P3-07-01: Circulating vitamin D concentrations and breast cancer risk: A pooled analysis of 17 cohorts. Cancer Res. 2015;75(9): Supplement.

86. Zamoiski RD, Freedman DM, Linet MS, Kitahara CM, Liu W, Cahoon EK. Prospective study of ultraviolet radiation exposure and risk of breast cancer in the United States. Environ Res. 2016;151:419-27.

87. Ma Y, Zhang P, Wang F, Yang J, Liu Z, Qin H. Association between vitamin $D$ and risk of colorectal cancer: a systematic review of prospective studies. J Clin Oncol. 2011;29(28):3775-82.

88. Sherman JE, Spencer J, Preisser JS, Gesler WM, Arcury TA. A suite of methods for representing activity space in a healthcare accessibility study. Int J Health Geogr. 2005:4(1):24.

89. Coutts C, Chapin T, Horner M, Taylor C. County-level effects of green space access on physical activity. J Phys Act Health. 2013;10(2):232-40.

90. Vanlint S. Vitamin D and obesity. Nutrients. 2013;5(3):949-56.

91. Centers for Disease Control and Prevention. Adult Obesity Prevalence Maps. https://www.cdc.gov/obesity/data/prevalence-maps.html. Accessed 29 Apr 2017.

\section{Submit your next manuscript to BioMed Central and we will help you at every step:}

- We accept pre-submission inquiries

- Our selector tool helps you to find the most relevant journal

- We provide round the clock customer support

- Convenient online submission

- Thorough peer review

- Inclusion in PubMed and all major indexing services

- Maximum visibility for your research

Submit your manuscript at www.biomedcentral.com/submit 